\title{
Academic Procrastination in Study Habits and Its Relationship with Self-Reported Executive Functions in High School Students
}

Journal of Psychology and Neuroscience

Research Article

Ana G. Gutiérrez-García ${ }^{1 *}$, Miguel Huerta-Cortés ${ }^{2}$ and María Gerarda Landeros-Velazquez ${ }^{2}$

Correspondence author

\author{
${ }^{1}$ Laboratory of Neuropharmacology, Institute of Neuroethology, \\ Universidad Veracruzana
}

${ }^{2}$ Psychology School, Universidad Veracruzana

\author{
"Ana G. Gutiérrez-García \\ Universidad Veracruzana \\ Av. Dr. Luis Castelazo s/n, Col. Industrial \\ Ánimas, Xalapa 91190, Veracruz \\ Mexico \\ E-mail : angutierrez@uv.mx
}

Submitted : 27 Jan 2020 ; Published : 10 Feb 2020

\begin{abstract}
Procrastination is a widespread phenomenon in educational settings. This study aimed to determine the relationship between academic procrastination regarding study habits and self-reported executive functions in high school students. In a sample of 52 students, the following instruments were applied: Academic Procrastination Scale (APS), Study Habits Inventory (SHI), Behavior Rating Inventory of Executive Function (BRIEF ${ }^{\circledR}$ ) and as a control variable, anxiety was measured using the Beck Anxiety Inventory (BAI). The results indicated that high school students had moderate procrastination scores that were negatively correlated with the SHI scores. A significant correlation was also found between the APS and the scales associated with the Metacognition Index (MI) as measured by BRIEF ${ }^{\circledR}$. It is concluded that students who procrastinate have difficulty organizing, planning and assimilating school content. The implementation of strategies for study habits in high school students is suggested, which would result in an impact on their metacognition.
\end{abstract}

Keywords: Academic Procrastination, Study Habits, Executive Functions, Metacognition, Students

\section{Introduction}

Academic procrastination or intentional delaying behavior regarding homework or school activities is a widespread phenomenon in educational environments, which represents a serious threat to students because such procrastination can negatively affect learning, performance, academic self-efficacy and quality of life [1-3]. Procrastination, often established as a stable personality-like trait, refers to voluntarily delaying an important activity despite receiving negative results; for this reason, in recent decades, attempts have been made to understand the factors that generate and maintain this type of problematic behavior [4-7].

It is estimated that around $70-80 \%$ of university students dedicate themselves to postponing activities and of these students, $20 \%$ do so in a constant and problematic way [8]. Apparently, postponement is endemic within the university population and the literature is filled with examples of university students who chronically postpone events $[9,10]$. However, although postponement has been related to certain personality components, it does not mean that it is a non-modifiable behavior. When students are trained to set goals and achievements in order to complete tasks on time, the trait of postponement is reduced in students with procrastination tendencies $[1,7,11,12]$.
The planning of study activities is important during the transition from high school to university, because it is a key stage when students are close to making decisions about the choice of field regarding their university degree, but $15-20 \%$ of students have difficulty implementing such planning [7]. It is possible that 1) the aspect of a lack of training in adequate study habits would exacerbate academic procrastination in students who are near to entering university education and 2) students will have other work and personal activities to attend to [13]. In general, improvements in academic functioning, from childhood, have a far-reaching impact on an individual's ability to obtain a university degree, which would consequently increase the likelihood of finding and maintaining remunerated employment, to the benefit of the individual and the society in general [14].

Students face many challenges that require the continuous development of their skills and abilities, and their executive system is largely responsible for the simultaneous coordination of a series of cognitive processes with the aim of achieving goal- and task-oriented behavior [15]. Further, the general term of 'executive functions' is an applied to those skills that involve cognitive control and self-regulation [16]. Since academic procrastination is characterized by the intention to undertake a task and a lack of 
diligence to begin, develop or finish that task, the results of some studies indicate that people who undertake postponement usually experience problems regarding self-control, implying failures in self-regulation, which is a component of executive functioning [3-5, 17-19].

The components of executive functioning (such as self-control, working memory and planning) are significant predictors of academic postponement [7]. The results of the study by Gustavson, Miyake, and Hewitt \& Friedman indicate that procrastinators exhibit lower levels of executive skills compared to non-procrastinators. Further, procrastination occurs more frequently when people face a task they consider aversive, which can cause them to have unpleasant feelings or a negative mood (for example, anxiety) [20-22]. Studies using functional magnetic resonance imaging or functional MRI (fMRI) have suggested that procrastination could be attributed to hypoactivity of the ventromedial and ventrolateral prefrontal cortex [23, 24]. Other research suggests that the middle frontal gyrus and the orbitofrontal cortex are key structures of self-control and emotional regulation, which could play an important role in procrastination [25].

Since procrastination research involves difficulties in executive functioning (i.e., planning, time organization, constant attention, error learning, decision-making), the prefrontal cortex is a leading candidate for the investigation of such behavior. Some research has examined postponement and executive functioning [7]. Rabin et al. used the Behavior Rating Inventory of Executive Function - Adult Version, which is a self-report measure, and found statistically significant associations between the nine BRIEF ${ }^{\circledR}$ clinical subscales and academic postponement $[16,20]$. On the other hand, Gustavson et al, also reported that procrastination was related to reduced executive functioning, which is assessed through self-report of daily failures in the management of objectives. Recently, Renaldi et al, showed that people who 1) are better able to organize their time demands, 2) think about a possible schedule and 3) tend to be more exhaustive in their efforts, have a lower risk of procrastination [20]. These findings support the concept that executive functions and postponement behavior can be linked.

In everyday life, executive functions are indispensable for performing simple tasks, ranging from waking up in the morning and planning which activity will be carried out first, to thinking about how the planning time of schoolwork could be distributed. Therefore, procrastination is inversely correlated with acquiring and appropriating a system where discipline is applied to the undertaking of some work [2]. The student needs an optimal executive system to process information while 1) listening to a teacher's explanations, 2) identifying relevant information, 3) inhibiting irrelevant thoughts and 4) ignoring distractions [26]. Further, an optimal executive system is also necessary for managing time, study skills, planning, goal setting and selfcontrol $[7,27]$. Thus, academic procrastination can be understood as an existing barrier that influences both the student's learning and the possible performance that he or she may have before the fulfillment of school activities.

The management of cognitive skills in order to assimilate and transform school content requires the organization and planning of time within appropriate study environments. Study habits are the strategies that students put into practice during their studies so that they can carry out school activities [28]. But, these study habits are also related to many cognitive processes that in turn relate precisely to self-regulation, planning, organization of materials and metacognition. Therefore, self-perception of the executive functions themselves refers to the perception that people have about their abilities to initiate, maintain and finish a task that is focused on a goal [16]. Inadequate management of study habits can lead students to drop-out, present poor school performance or present difficulties in the acquisition process and learning strategies, which are all coupled with difficulties in associated processes regarding self-regulation and metacognition $[29,30]$. Understanding the relationship between these processes will help to have better prevention strategies in order to design more effective and efficient educational support systems for students [7].

With the background that is described in the above, the following hypothesis was generated for the present study: Procrastination is related to the inadequate study habits of the student with respect to fulfilling his or her academic activities on time and in turn those study habits are dependent on the cognitive processes that make it possible for such habits to be effected. Therefore, the main objective of this research was to 1) determine whether academic procrastination is related to study habits and 2) determine whether academic procrastination is in turn related to the executive functions that high school students possess, in addition to 3) providing data that can be complementary to an analysis of anxiety levels that could be associated with academic procrastination. No specific hypothesis was generated about the relationship between procrastination and gender or age, given the size of the sample.

\section{Methods}

\section{Ethical considerations}

Across-correlational study was conducted, with a research protocol that was approved by the Ethics Committee of the University Veracruzana, Mexico (Registration No. CEI-PSI/002/2015). All participants signed an informed consent, in addition to the collection of an informed consent with the signature of the principal guardian of the participant, complying with the provisions of the international codes of ethics adopted by the 18th World Medical Association (WMA) General Assembly (June 1964) Declaration of Helsinki in Finland and its later amendments.

\section{Participants}

A non-probability sampling was carried out for convenience, from which a sample consisting of 52 young students from a public high school was obtained. All participants were enrolled in the regular February-July 2019 period (i.e., USA grade range of 9-12).

\section{Instruments}

\section{Academic Procrastination Scale (APS)}

The Academic Procrastination Scale (APS) used was that of Busko (1998) which was translated by Álvarez (2010) and adapted by Barraza \& Barraza (2014) for the Mexican population using a sample of 361 high school students [31-33]. The APS consists 
of 12 items with five response options (never, rarely, sometimes, almost always, always), assigning each question a score of 1 (never) to 5 (always). It has a good internal consistency, with a Cronbach's alpha $=0.816$. With the APS, high scores above 75 indicate a high level of procrastination [34].

\section{Study Habits Inventory (SHI)}

The Study Habits Inventory (SHI) of Fernández-Pozar (28) was used in the present study. The SHI is an instrument that can be applied individually or collectively to individuals of $12 \mathrm{yrs}$ of age and older. Its duration is approximately $15 \mathrm{~min}$. It consists of 90 items, distributed over 4 scales as follows: I) Environmental conditions of study, consisting of 18 items that evaluate the characteristics of the environment surrounding the student, such as personal and physical environment, academic behavior, and performance. The maximum score for this scale is 33 points; II) Study planning: with 12 responses that inquire about: planning of the study in schedules, rest spaces, organization of the materials and elements necessary for the study. The maximum score for this scale is 33 points; III) Use of materials: through 15 responses, this scale establishes the handling of books, reading and summaries. The maximum score for this scale is 24 points; IV) Content assimilation: this scale consists of 15 items that assess the degree of memorization and personalization in reference to personal and teamwork. The maximum score for this scale is 30 points. In addition to the above, the inventory includes: V)Analysis regarding sincerity with a maximum score of 30 points. Adaptations of the test have been made for the Mexican population in a sample of 250 high school students chosen randomly, with a validity coefficient of 0.85 . The norm of interpretation is realized by means of the creation of scales, where the higher values indicate a greater endowment of the evaluated aptitude. Enneatypes constitute a typical scale ranging from 1-9, with scores between enneatypes 4 and 6 reflecting performance within the normal range; with scores between enneatypes 7 and 9 reflecting performance from good to excellent, and scores between enneatypes 1 to 3 , reflecting performance from bad to unsatisfactory.

\section{Behavior Rating Inventory of Executive Function (BRIEF $\left.{ }^{\circledR}\right)$}

The Behavior Rating Inventory of Executive Function - Adult Version, is a paper-and-pencil assessment of 75 questions with nine scales measuring self-perception about the executive functioning itself [16]. BRIEF ${ }^{\circledR}$ uses a Likert scale with 3 response options $(1=$ never; $2=$ sometimes; $3=$ often $)$. The duration of the test is approximately $15 \mathrm{~min}$. Since the sample of the present study covered a range of students under and over 18 yrs of age, it was decided to use the Behavior Rating Inventory of Executive Function - Adult Version $\left(\right.$ BRIEF $^{\circledR}$-A), given the high similarities between the Behavior Rating Inventory of Executive Function Self-Report Version (BRIEF ${ }^{\circledR}$-SR) that is designed for teenagers and the BRIEF $^{\circledR}-A$ that is designed for individuals in the age range of 18 to 90 yrs, according to Pope, Ross \& Stavrinos [35].

The application and usage of the test with the version approved for application in the Spanish language, was granted special permission by the publisher: Psychological Assessment Resources (PAR), Inc., 16204 North Florida Avenue, Lutz, Florida 33549, USA, regarding the use of The Behavior Rating Inventory of
Executive Function - Adult Version $\left(\mathrm{BRIEF}^{\circledR}-\mathrm{A}\right)$ by Robert M. Roth $\mathrm{PhD}$, Peter K. Isquith $\mathrm{PhD}$, and Gerard $\mathrm{A}$. Gioia $\mathrm{PhD}$; Copyright 1996, 1998, 2001, 2003, 2004, 2005 by PAR).

The instrument has nine subscales, which are made up of inhibition, shifting, emotional control, self-monitoring, initiative, working memory, plan/organization, task monitoring, and organization of materials. The subscales are described here: i) the inhibition scale contains 8 items that measure the regulation of behavior or the ability not to act on impulse; ii) the shifting scale contains 6 items that measure the ability to change behaviorally or cognitively from one situation, activity or aspect of one problem to another, as circumstances require; iii) the emotional control scale contains 10 items referring to the person's ability to modulate emotional responses; iv) the self-control scale contains 6 reagents that assess the extent to which a person tracks their own behavior and their impact on others. The sum of these four scales gives rise to an index of self-regulation known as the Behavioral Regulation Index (BRI).

The Metacognition Index (MI) covers v) the initiative scale that contains 8 items related to the ability to start a task and independently generate ideas, answers or problem-solving strategies; vi) the working memory scale contains 10 items, which assess the extent to which information retention capacity is used to generate a response or complete a task; vii) the plan/ organization scale contains 10 items that assess the ability to manage the demands of present- and future-oriented tasks within their situational contexts; viii) the monitoring scale contains 6 elements that assess how an individual keeps track of their success or failure in solving problems; and ix) the materials organization scale has 8 elements that assess order in the daily environment and they have the ability to track everyday objects, including tasks.

It is also possible to obtain the Global Executive Index (BRI + MI), which constitutes the sum of both the Behavior Regulation Index (BRI) and the Metacognition Index (MI). Higher scores in the BRIEF $^{\circledR}$ indicate more difficulties or alterations in the selfperception of executive functioning during the last month.

BRIEF $^{\circledR}$ has demonstrated high reliability (Cronbach's alpha $0.73-0.96)$, validity and clinical utility as an ecological product and it is sensitive to executive functioning in healthy individuals and also those individuals who have a wide range of psychiatric and neurological conditions [16].

\section{Beck Anxiety Inventory (BAI)}

The Beck Anxiety Inventory (BAI) is composed of 21 items. The participant is asked to indicate how often, within the last week, he or she has experienced any of the symptoms that make up the questionnaire using a four-point scale that ranges from 0 (nothing or little) to 3 (severely) [36]. The total sum of the points allows a maximum of 63 to be obtained; hence, the severity of anxiety is measured [37]. Scores below 21 indicate low anxiety, scores from 22 to 35 correspond to moderate anxiety, and scores greater than or equal to 36 denote severe anxiety. In the present study, the version that is translated into Spanish and is validated for the Mexican population was used, and it has an internal consistency with a Cronbach's alpha of 0.83 in a sample of adults [38]. 


\section{Procedure}

An open call was made on the campus of a Mexican public upper secondary school (i.e., high school) to participate in the research. Students were informed that the study consisted of completing a series of paper-and-pencil questionnaires on the general theme of academic motivation that would take approximately 40-50 min. Participation was voluntary and confidential. The students were also required to deliver an informed consent letter signed by their main tutor. The instruments were applied midway through the school period. The instruments were applied in the following sequence: Academic Procrastination Scale (APS), followed by the Study Habits Inventory (SHI), then the Behavior Rating Inventory of Executive Function $\left(\right.$ BRIEF $\left.^{\circledR}\right)$, followed by the Beck Anxiety Inventory (BAI).

The tests used were applied and scored according to the standardized form described in the instruction manuals and also by qualified personnel.

\section{Data analysis}

Excel spreadsheet software was used for organizing the data and Sigma 12.0 statistical package was used to prepare the resulting databases. Descriptive statistics were calculated for all variables. This study analyzed the data of the participants as a unit group (i.e., rather than dividing the participants into high versus low scores). The raw scores of each participant that were obtained from the measures of executive functioning $\left(\mathrm{BRIEF}^{\circledR}\right)$, procrastination (APS), study habits (SHI) and anxiety (BAI) were used.

Based on the objective of identifying the relationships between academic procrastination, study habits and executive functions in young people, bivariate correlations were made, using Spearman's correlation coefficient because the variables did not have a normal distribution. The level of statistical significance was set at $\mathrm{p}<0.05$.

\section{Results}

\section{Sample characteristics}

The descriptive statistics are shown in Table 1. A total of 52 students participated of which there were 36 women $(69.2 \%)$ and 16 men (30.8\%). The average age of the students was $17 \mathrm{yrs}$ (significant difference, $\mathrm{SD}=0.95$ ), in an age range of 15 to $19 \mathrm{yrs}$.

The average academic procrastination scores were within the moderate range, given that scores $>75$ and $<25$ indicate high and low levels, respectively; the scores varied from a min. of 33 to a max. of 50 .

In the scale of environmental conditions of study within the SHI, $52 \%$ of the students were in the normal category, $27 \%$ were in the good to excellent category, while $21 \%$ were in the bad to unsatisfactory category. Regarding the planning of the study related to the organization and the establishment of schedules, it is evident that a significant percentage of students (87\%) were in the category of normal to excellent, but $14 \%$ of students were in the bad to unsatisfactory category, which implies a need to review the strategies used by students in order to properly plan and organize the activities related to the student's role and, in general, with the student's daily life habits. As for the use of materials, again $23 \%$ of the sample had difficulties and $17 \%$ also had difficulties in the assimilation of the contents. Finally, the sincerity of the students was evaluated when answering the questions, and approximately $30 \%$ were not honest in answering the questions that were asked through the inventory.

The average $\mathrm{BRIEF}^{\circledR}$-A scores were within the normal range (defined as a score of $\mathrm{T}<65$ ). The crude scores obtained were within the normal range and they were similar to those score reported by Poper et al. (2016) and Rabin et al. (2011) [7]. The average anxiety was in the low range, with scores ranging from minimum to moderate.

\begin{tabular}{|c|c|c|}
\hline Variables & Mean (SD) & $\%(n)$ \\
\hline Age (yrs) & $16.5(0.95)$ & \\
\hline \multicolumn{3}{|l|}{ Gender } \\
\hline Male & & $69.2(36)$ \\
\hline Female & & $30.8(16)$ \\
\hline Procrastination & $41.6(3.98)$ & \\
\hline \multicolumn{3}{|l|}{ SHI } \\
\hline Scale I & $21.6(4.88)$ & \\
\hline Scale II & $12.1(4.90)$ & \\
\hline Scale III & $16.0(4.63)$ & \\
\hline Scale IV & $21.0(3.75)$ & \\
\hline \multicolumn{3}{|l|}{$\mathrm{BRIEF}^{\circledR}-\mathrm{A}$} \\
\hline Inhibition & $14.0(3.14)$ & \\
\hline Shifting & $9.6(2.33)$ & \\
\hline Emotional control & $19.0(5.45)$ & \\
\hline Self-monitoring & $9.9(2.75)$ & \\
\hline BRI & $52.7(10.46)$ & \\
\hline Initiation & $13.2(2.98)$ & \\
\hline Working memory & $13.6(3.26)$ & \\
\hline $\begin{array}{l}\text { Planning/ } \\
\text { Organizing }\end{array}$ & $16.7(3.77)$ & \\
\hline Task Monitoring & $10.4(1.99)$ & \\
\hline $\begin{array}{l}\text { Organization of } \\
\text { Materials }\end{array}$ & $13.6(3.49)$ & \\
\hline MI & $67.7(12.28)$ & \\
\hline $\mathrm{BRI}+\mathrm{MI}$ & $120.5(19.28)$ & \\
\hline BAI & $21.5(12.00)$ & \\
\hline
\end{tabular}

Table 1: Descriptive statistics for the sample of 52 undergraduate students.

Notes: $\mathrm{SD}=$ standard deviation,

$\mathrm{SHI}=$ Study Habits Inventory

$\mathrm{BRIEF}^{\circledR}-\mathrm{A}=$ Behavior Rating Inventory of Executive Function Adult Version

$\mathrm{BAI}=$ Beck Anxiety Inventory

$\mathrm{BRI}=$ Behavior Regulation Index

$\mathrm{MI}=$ Metacognition Index 
Table 2 describes the correlations found between study habits and academic procrastination. A moderate but significant negative correlation was found between the APS and environmental conditions of the study ( $p<0.01$ ), planning towards the study $(\mathrm{p}<0.001)$, as well as in the assimilation of contents $(p<0.02)$; that is to say, the more the student postpones activities, the lower his or her scores are in some of his or her study habits, and mainly in those scores related to the environmental conditions of the study, planning to study and in the assimilation of contents.

\begin{tabular}{|l|l|l|}
\hline Dimensions of SHI & $\mathrm{r}$ & $\mathrm{P}$ \\
\hline $\begin{array}{l}\text { Scale 1: environmental conditions of } \\
\text { the study }\end{array}$ & -0.333 & $<0.01^{*}$ \\
\hline Scale 2: study planning & -0.429 & $<0.001^{*}$ \\
\hline Scale 3: utilization of materials & -0.073 & $0.604, \mathrm{NS}$ \\
\hline Scale 4: assimilation of contents & -0.309 & $<0.02^{*}$ \\
\hline Additional scale : Sincerity & 0.054 & $0.700, \mathrm{NS}$ \\
\hline
\end{tabular}

Table 2. Correlations between the different scales measured by the SHI and the APS in high school students.

Notes: $*=$ significant correlations;

$\mathrm{NS}=$ non-significant correlations.

Table 3 shows the correlations obtained between the APS, with respect to scores obtained in the $\mathrm{BRIEF}^{\circledR}-\mathrm{A}$. We found weak to moderate but significant correlations between the postponement of activities with all the subscales of the $\mathrm{BRIEF}^{\circledR}$-A that are related with the Metacognition Index (MI): initiative, working memory, planning-organization, task monitoring, and the organization of materials.

\begin{tabular}{|l|l|l|}
\hline BRIEF $^{\circledR}$-A & $\mathrm{r}$ & $\mathrm{P}$ \\
\hline Inhibition & 0.252 & $0.07, \mathrm{NS}$ \\
\hline Shifting & 0.250 & $0.07, \mathrm{NS}$ \\
\hline Emotional control & 0.014 & $0.916, \mathrm{NS}$ \\
\hline Automonitoring & 0.081 & $0.564, \mathrm{NS}$ \\
\hline Behavior Regulation Index (BRI) & 0.186 & $0.224, \mathrm{NS}$ \\
\hline Initiative & 0.318 & $<0.02^{*}$ \\
\hline Working memory & 0.288 & $<0.03^{*}$ \\
\hline Planning/organization & 0.303 & $<0.02^{*}$ \\
\hline Monitoring of tasks & 0.316 & $<0.02^{*}$ \\
\hline Organization of materials & 0.284 & $<0.04^{*}$ \\
\hline Metacognition Index (MI) & 0.356 & $<0.009^{*}$ \\
\hline Global Index (BRI+MI) & 0.315 & $<0.02^{*}$ \\
\hline
\end{tabular}

Table 3. Correlations between the different scales measured by the BRIEF ${ }^{\circledR}$-A and the APS in high school students.

Notes: * = significant correlations;

NS $=$ non-significant correlations.
Table 4 shows the correlations obtained between the BRIEF $^{\circledR}-\mathrm{A}$ and the SHI. Moderate negative correlations were found between inhibition and change in relation to the study conditions and study planning. The change was also related to the content assimilation scale. The Behavioral Regulation Index (BRI) was negatively and moderately correlated with both the environmental conditions in which a student studies and the study planning. Regarding the Metacognition Index, the highest correlations were established with the scale of environmental conditions for studying and study planning.

\begin{tabular}{|l|l|l|l|l|l|}
\hline BRIEF $^{\circledR}$-A & Scale 1 & Scale 2 & Scale 3 & Scale 4 & Scale 5 \\
\hline Inhibition & $-0.408^{*}$ & $-0.313+$ & -0.191 & -0.255 & -0.087 \\
\hline Shifting & $-0.308^{+}$ & $-0.418^{*}$ & 0.0451 & $-0.291+$ & 0.245 \\
\hline $\begin{array}{l}\text { Emotional } \\
\text { control }\end{array}$ & -0.236 & -0.133 & -0.004 & -0.044 & -0.057 \\
\hline Automonitoring & -0.164 & -0.170 & -0.211 & -0.200 & 0.197 \\
\hline (BRI) & $-0.345+$ & $-0.325+$ & -0.056 & -0.176 & 0.178 \\
\hline Initiative & $-0.503^{*}$ & $-0.569^{* *}$ & -0.051 & $-0.316+$ & 0.234 \\
\hline $\begin{array}{l}\text { Working } \\
\text { memory }\end{array}$ & $-0.382^{*}$ & $-0.306+$ & $-0.284+$ & $-0.440^{*}$ & $0.317+$ \\
\hline $\begin{array}{l}\text { Planning/ } \\
\text { organization }\end{array}$ & $-0.413^{*}$ & $-0.526^{* *}$ & -0.143 & -0.195 & 0.168 \\
\hline $\begin{array}{l}\text { Monitoring of } \\
\text { tasks }\end{array}$ & $-0.274+$ & $-0.376^{*}$ & -0.096 & $-0.307+$ & 0.224 \\
\hline $\begin{array}{l}\text { Organization of } \\
\text { materials }\end{array}$ & $-0.306^{+}$ & $-0.422^{*}$ & -0.191 & -0.097 & 0.125 \\
\hline MI & $-0.481^{* *}$ & $-0.567^{* *}$ & -0.230 & $-0.319+$ & 0.247 \\
\hline BRI+MI & $-0.476^{* *}$ & $-0.512^{* *}$ & -0.199 & $-0.308+$ & 0.265 \\
\hline
\end{tabular}

Table 4. Correlations between the different scales measured by the BRIEF $^{\circledR}-\mathrm{A}$ and the 5 scales of the SHI in high school students

Notes: $+\mathrm{p}<0.01$

$* \mathrm{p}<0.001$;

$* * \mathrm{p}<0.0001$;

Abbreviations: BRI, Behavioral Regulation Index;

MI, Metacognition Index; BRI+MI, Global Index.

\section{Discussion}

The aim of this study was to determine the relationship that academic procrastination could have with study habits and self-perception in executive functions, along with anxiety (i.e., potentially an element associated with academic procrastination). The study results indicate that the high school students had moderate procrastination scores and that this was related to a low level of good study habits in terms of environmental conditions, planning to study and assimilation of content, that is, that the students who were procrastinating the most had difficulties in planning and organizing their school activities and establishing the optimal environmental conditions for them. In addition, the entire Metacognition Index was positively correlated with procrastination and negatively correlated with difficulties in study habits; specifically those related to environmental conditions, planning and content assimilation. 
While it is not surprising that initiation, planning and organizational skills were predictive of academic procrastination and inadequate study habits, these results suggest the importance of working with students to improve these skills. Optimizing strategies in study habits involves teaching students to set short- to medium-term objectives for their academic work, together with reasonable expectations concerning the amount of effort required to complete a given task $[39,40]$.

The environmental conditions of study imply that via training the student could find a fixed place to work, whereby he or she can concentrate, and be removed from noise and distractions, while work at a clean desk, in a well-ventilated place with adequate lighting [28]. All these factors would increase the cognitive ability of self-control and avoid distraction in order to access short-term situations [41]. Likewise, peer monitoring of responsibility and consequences for behavioral failures constitute a method of selfevaluation (for example, self-tests with mastery criteria included) that can also improve academic awareness [42]. Having a study schedule, fulfilling it and also having a proactive attitude towards making summaries, worksheets, among others, can help students find appropriate ways to organize their study tasks in a beneficial way [28].

The students in this study were evaluated regarding anxiety in the middle of the school period and no correlation was found between procrastination and anxiety. Similarly, in other studies, anxiety does not appear to be related to procrastination and it is suggested that it should be examined and interpreted in the context of its relationship with other variables [7, 43]. Consequently, future research could assess anxiety and other mood disorders for longer periods of time or at various stages of the school period. Research that uses repeated assessments of anxiety during an academic semester supports the idea that procrastinators tend to experience less stress at the beginning of the semester and higher levels of anxiety as the end of the semester approaches [7, 44].

It has been known for some time that the prefrontal cortex does not fully develop until the mid-20s [45]. Consequently, a population of high school students may require more time to make full use of their executive functioning skills. Consciousness is a trait that reflects responsibility, self-discipline, motivation for achievement, and diligent care and fulfillment of obligations, hence low awareness is a predictor of procrastination [36]. Students who participated in the present study, with an average age of $17 \mathrm{yrs}$, can still show low levels of self-regulation and metacognition [41]. Therefore, the implementation of the study techniques was focused on the organization and stimulation of self-control, which can promote self-regulation, together with techniques for achieving motivation, which in turn can intrinsically help more students and other young people to set academic goals and enjoy their learning experience, thus reducing the task-aversion impediment that can occur with academic task fulfillment [46]. As a result, school districts and higher education facilities could benefit if the problems are identified during the earlier stages. For example, in undergraduate students who are attending high school, procrastination tendencies could be channeled into an intensive management program regarding time, organization and decisionmaking before entering the university, and thereby maximize the probability of student success through appropriate study habits, which in turn could promote metacognition [10].

Metacognition is crucial in the control and guidance of thinking [47]. It implies cognitive ability with which to solve problems in a systematic way through planning and organization, while seeking to complete tasks using active working memory [16] . Dunlosky $\&$ Thiede [48] proposed a model of how metacognitive control impacts study time. This model includes preparing the study (i.e., evaluation of self-efficacy, evaluation of tasks, and selection of initial strategy), monitoring and evaluation of the elements that must be learned, and the procurement of feedback, which implies that in the case of non-achievement of learning some elements of what has been studied, the material can then be studied again.

In general, students are unaware of effective study strategies or habits that can affect their performance [49-51]. However, metacognition training involves strengthening three cognitive skills: planning, monitoring and evaluation [52]. That is, metacognitive knowledge implies the handling of information that is consulted when thinking about an idea and includes basic facts and concepts (which implies the use of working memory). Metacognitive monitoring is the ability to assess cognitive activity, while metacognitive control is the ability to regulate cognitive activity [51].

Planning and monitoring are components of metacognition, which guides our learning strategies. When students participate in planning activities, they think about what they need to learn and set specific objectives for the task [53]. Once they have undertaken planning, they then need to monitor the experience, which refers to paying attention to the performance and understanding of the course material [54]. Monitoring is a critical component of self-regulation because it brings awareness of one's level of knowledge, which then leads to changes in affect, cognition and behavior, thus improving learning regulation by providing feedback on what students already know and where they need to focus their resources [54-56]. If students recognize what they do know and also what they do not know, this can facilitate the acquisition of the required knowledge by helping those students to obtain such information by self-directing and self-regulating their own learning. Finally, simply being aware or being aware of metacognition can help a student avoid mistakes, because the increased awareness of the thinking process itself leads to better critical thinking and monitoring of actions [47].

Suggestions for teaching metacognitive skills in the didactic environment include cognitive learning, exam reviews, models of metacognitive skills, thinking out loud, protocols, reflection tasks, self-explanatory methods, and judgment of comprehension tasks [57]. In the experimental environment, faculty members can emphasize the establishment of student mastery learning objectives, using questioning techniques that promote metacognitive awareness along with comments on student efforts in this area, and the promoting of scaffolding as a teaching approach. In general, the use of these teaching strategies, regardless of the environment, can increase students' selfawareness and help generate metacognitive thinking that becomes more automatic at a later stage [58]. 
The creation and application of a metacognitive model during the school stages prior to entering university, which is supported by the use of appropriate study habit strategies, can be a useful approach to avoid procrastination behavior in the university educational environment [59]. In consistency, significant associations have been found between academic performance and negative metacognitions with procrastination, hence, the creation of novel interventions based on metacognitions can help decrease the behavior of procrastination and optimize the academic performance of students [60].

\section{Study limitations}

The main limitation of this research was the size of the study sample and not having equal numbers of women and men that would establish a gender difference. Another limitation is that which exists when the informants are the students themselves, and the APS, the SHI and the BRIEF ${ }^{\circledR}$ evaluate self-perception, which can always contain a problem of bias from the perspective of the informant. In addition, the results of the SHI found that more than $30 \%$ of respondents were not honest when answering the inventory. In future, research other measurement strategies that involve the execution by the individual and the information of the academic staff should be used, in addition to considering, for example, variables related to school performance.

\section{Future prospects resulting from this study}

Through this research, better decisions can be made regarding the promotion of strategies to improve the study habits of students, seeking to reduce indicators over the medium- or long term such as dropping out of school. The results of this research can provide preliminary information on the relationship between procrastination, study habits and the self-perception of effectiveness that students have on their executive functions, in the context of high school students, in order to help them to move successfully to the demands of higher education. The SHI can provide possible strategies to develop adequate study habits. A model similar to that proposed by Fernie et al. involves working directly with the improvement of students' metacognitive processes, which in turn will impact on the management of better school performance and produce a decrease in procrastination [60]. All these factors should be considered as preventive actions that educational psychologists and teaching staff could implement in the school environment.

\section{Conclusions}

Regarding the study sample, it was found that during high school students have a moderate level of procrastination, which is related to study habits, in that as long as the student postpones school activities he or she will have difficulty planning his or her studies and assimilating the content. This in turn is related to the level of metacognition that students have.

\section{Acknowledgements}

The authors thank Professor Teresita Inés for providing all the logistical support for the application of the instruments to the students participating in the public education school.

\section{References}

1. Domínguez-Lara S, Prada-Chapoñan R, Moreta-Herrera R (2019) Gender differences in the influence of per-sonality on academic procrastination in Peruvian college students. Acta Colombiana de Psicología 22: 125-136.

2. Sabri Y, Hamdy I, El-Wasify M, Saleh ES (2019) Causal attributions and executive functions of academic procrastination in Mansoura University students. Egyptian Journal of Psychiatry 37: 70-78.

3. Sirois F, Pychyl T (2013) Procrastination and the priority of short-term mood regulation: consequences for future self. Social and Personality Psychology Compass 7: 115-127.

4. Klingsieck KB (2013) Procrastination when good things don't come to those who wait European Psychologist 18: 2434.

5. Rozental A, Carlbring P (2014) Understanding and treating procrastination: A review of a common self-regulatory failure. Psychology 5: 1488-1502.

6. Sirois FM (2014) Absorbed in the moment? An investigation of procrastination, absorption and cognitive failures. Personality \& Individual Differences 71: 30-34.

7. Rabin LA, Fogel J, Nutter-Upham KE (2011) Academic procrastination in college students: The role of self-reported executive function. Journal of Clinical and Experimental Neuropsychology 33: 344-357.

8. Esteban RFC, Ramírez A (2014) Procrastination and demographic characteristics associated with college students. Tehran University Medical Journal 72: 113-120.

9. Milgram NA, Naaman N (1996) Typology in procrastination. Personality \& Individual Differences 20: 679-683.

10. Rinaldi AR, Roper CL, Mehm J (2019) Procrastination as evidence of executive functioning impairment in college students. Applied Neuropsychology: Adult 4: 1-10.

11. Ackerman DS, Gross BL (2005) My instructor made me do it: Task characteristics of procrastination. Journal of Marketing Education 27: 5-13.

12. Seo EH (2011) The relationships among procrastination, flow, and academic achievement. Social Behavior and Personality: and International Journal 39: 209-217.

13. Arnett JJ, Žukauskienè R, Sugimura K (2014) The new life stage of emerging adulthood at ages 18-29 years: Implications for mental health. The Lancet Psychiatry 1: 569-576.

14. Arbona C (2000) The development of academic achievement in school aged children: Precursors to career development. In S. D. Brown \& R. W. Lent (Eds.), Handbook of counseling psychology 2000: 270-309.

15. Randolph JJ, Chaytor NS (2013) Promoting the executive functions: Core foundations, assessment considerations, and practical applications.Positiveneuropsychology:evidence-based perspectives on promoting cognitive health 2013:77-101. 
16. Roth RM, Isquith PK, Gioia GA (2005) BRIEF-A: Behavior rating inventory of executive function--adult version: Professional manual. North Florida, U.S.A: Psychological Assessment Resources (PAR).

17. Effert BR, Ferrari JR (1989) Decisional procrastination: examining personality correlates. Journal of Social Behavior and Personality 4: 151-161.

18. Steel P (2007) The nature of procrastination: A meta-analytic and theoretical review of quintessential self-regulatory failure. Psychological Bulletin 133: 65-94.

19. Steel P, Klingsieck K (2015) Procrastination. In J. D. Wright (Ed.), the international Encyclopedia of the Social \& Behavioral Sciences 19: 73-78.

20. Gustavson DE, Miyake A, Hewitt JK, Friedman NP (2015) Understanding the cognitive and genetic underpinnings of procrastination: Evidence for shared genetic influences with goal management and executive function abilities. Journal of Experimental Psychology General 144: 1063-1079.

21. Van Eerde W (2003)A meta-analytically derived nomological network of procrastination. Personality \& Individual Differences 35: 1401-1418.

22. Stöber J, Joormann J (2001) Worry, procrastination, and perfectionism: differentiating amount of worry, pathological worry, anxiety, and depression. Cognitive Therapy and Research 25: 49-60

23. Zhang W, Wang X, Feng $T$ (2016) Identifying the neural substrates of procrastination: A resting-state fMRI study. Scientific Reports 6: 33203.

24. Wu Y, Li L, Yuan B, Tian X (2016) Individual differences in resting-state functional connectivity predict procrastination. Personality and Individual Differences 95: 62-67.

25. Hu Y, Liu P, Guo Y, Feng T (2018) The neural substrates of procrastination: A voxel-based morphometry study. Brain Cognition 121: 11-16.

26. Diamond A (2014) Want to optimize executive functions and academic outcomes? Simple, just nourish the human spirit. Minnesota Sympsia on Child Psychology 37: 205-232.

27. Fuhs MW, Nesbitt KT, Farran DC, Dong N (2014) Longitudinal associations between executive functioning and academic skills across content areas. Develomental Psychology 50: 1698-1709.

28. Fernández-Pozar F (2014) Inventario de hábitos de estudio. Madrid, España: TEA Ediciones SAU.

29. Parìs SG, Parìs AH (2001) Classroom applications of research on self-regulated learning. Educational Psychologist 36: 89101.

30. Rodríguez A, Clariana M (2017) Procrastinación en estudiantes universitarios: su relación con la edad y el curso académico. Revista Colombiana de Psicología 26: 45-60. and procrastination: a structural equation model (Doctoral dissertation).http://citeseerx.ist.psu.edu/viewdoc/ download?doi=10.1.1.456.4450\&rep=rep1\&type $=$ pdf

32. Álvarez O (2010) Procrastinación general y académica en una muestra de estudiantes de secundaria de Lima metropolitana. Persona 13: 159-177.

33. Barraza A, Barraza S (2018) Evidencias de validez y confiabilidad de la escala de procrastinación académica en una población estudiantil mexicana. Revista de Psicología y Ciencias del Comportamiento de la Unidad Académica de Ciencias Jurídicas y Sociales 9: 75-99.

34. Domínguez-Lara S (2016) Datos normativos de la escala de procrastinación académica en estudiantes de psicología de Lima. Revista Evaluar 16: 20-30.

35. Pope CN, Ross LA, Stavrinos D (2016) Association between Executive Function and Problematic Adolescent Driving. Journal Development Behavior Pediatric 37: 702-711.

36. Robins RW, Fraley RC, Roberts BW, Trzesniewski KH (2001) A longitudinal study of personality change in young adulthood. Journal of Personality 69: 617-640.

37. Beck AT, Steer RA (1993) Beck Anxiety Inventory Manual. San Antonio, TX: Psychological Corporation.

38. Robles-García R, Varela R, Jurado S, Páez F (2001) The Mexican version of Beck Anxiety Inventory: Psychometric properties. Revista Mexicana de Psicología 18: 211-218.

39. Ariely D, Wertenbroch K (2002) Procrastination, deadlines, and performance: Self-control by recommitment. Psychological Science 13: 219-224.

40. Tuckman BW (1998) Using tests as an incentive to motivate procrastinators to study. Journal of Experimental Education 66: 141-147.

41. Schouwenburg HC, Groenewoud JT (2001) Study motivation under social temptation: Effects of trait procrastination. Personality and Individual Differences 30: 229-240.

42. Tuckman B, Schouwenburg HC (2004) Behavioral interventions for reducing procrastination among university students. In H. C. Schouwenburg, C. H. Lay, T. A. Pychyl, \& J. R. Ferrari (Eds.), Counselling the Procrastinator in Academic Settings 2004: 91-103.

43. Haycock LA, McCarthy P, Skay CL (1998) Procrastination in college students: The role of self-efficacy and anxiety. Journal of Counseling and Development 76: 317-324.

44. Tice DM, Baumeister RF (1997) Longitudinal study of procrastination, performance, stress and health: The costs and benefits of dawdling. Psychological Science 8: 454-458.

45. Gledd J, Blumenthal J, Jeffries NO, Castellanos FX, Liu $\mathrm{H}$, et al. (1999) Brain development during childhood and adolescence: A longitudinal MRI study. Nature Neuroscience 2: 861-863.

31. Busko DA (1998) Causes and consequences of perfectionism 
46. Spence JT, Helmreich RL (1983) Achievement-related motives and behavior. In J. T. Spence (Ed.), Achievement and achievement motives: Psychological and Sociological Approaches 1983: 10-74.

47. Medina MS, Castleberry AN, Persky AM (2017) Strategies for improving learner metacognition in health professional education. American Journal of Pharmaceutical Education 81: 1-14.

48. Dunlosky J, Thiede KW (1998) What makes people study more? An evaluation of factors that affect self-paced study. Acta Psychologica 98: 37-56.

49. Karpicke J, Butler A, Roediger HL (2009) Metacognitive strategies in student learning: do students practice retrieval when they study on their own? Memory 17: 471-479.

50. Carrier LM (2003) College students' choices of study strategies. Perceptual and Motor Skills 96: 54-56

51. Bjork RA, Dunlosky J, Kornell N (2013) Self-regulated learning: beliefs, techniques, and illusions. Annual Review Psychology 64: 417-444.

52. Dunlosky J, Metcalfe J (2009) Metacognition. Los Angeles, CA: SAGE Publications, Inc.

53. Pintrich PR (2000) Issues in self-regulation theory and research. Journal Mind and Behavior 21: 213-219.

54. Kanfer R, Ackerman PL (1989) Motivation and cognitive abilities - an integrative aptitude treatment interaction approach to skill acquisiton. Journal of Applied Psychology 74: 657-690.

55. Zimmerman BJ (2000) Self-efficacy: an essential motive to learn. Contemporary Educational Psychology 25: 82-91.

56. Dunlosky J, Kubat-Silman AK, Hertzog C (2003) Training monitoring skills improves older adults' self-paced associative learning. Psychology and Aging 18: 340-345.

57. Hacker DJ, Dunlosky J (2003) Not all metacognition is created equal. New Directions for Teaching \& Learning 2003: 73-79.

58. Marcum JA(2012) An integrated model of clinical reasoning: dual-process theory of cognition and metacognition. Journal of Evaluation in Clinical Practice 18: 954-961.

59. Fernie B, Bharucha Z, Nikčević A, Marino C, Spada M (2017) A metacognitive model of procrastination. Journal of Affective Disorders 210: 196-203.

60. Fernie B, Kopar U, Fisher P, Spada M (2018) Further development and testing of the metacognitive model of procrastination: self-reported academic performance. Journal of Affective Disorders 240: 1-5.

Copyright: (C2020 Ana G. Gutiérrez-García This is an open-access article distributed under the terms of the Creative Commons Attribution License, which permits unrestricted use, distribution, and reproduction in any medium, provided the original author and source are credited. 